\title{
SPIE's School Outreach Activity Program (SOAP) by IIT Madras SPIE Student Chapter: a review
}

Lavanya Kalikivayi, V. Kalikivayi, K. Udayakumar, A. Ganesan

Lavanya Kalikivayi, V. Kalikivayi, K. Udayakumar, A. R. Ganesan, "SPIE's School Outreach Activity Program (SOAP) by IIT Madras SPIE Student Chapter: a review," Proc. SPIE 9188, Optics Education and Outreach III, 91880I (15 September 2014); doi: 10.1117/12.2061590

EDIE Event: SPIE Optical Engineering + Applications, 2014, San Diego, California, United States 


\title{
SPIE's School Outreach Activity Program (SOAP) by IIT Madras SPIE Student Chapter: A Review Lavanya Kalikivayi ${ }^{1}$, V.Kalikivayi ${ }^{2}$, K. Udayakumar ${ }^{2}$ and A.R.Ganesan ${ }^{2}$
}

1. KVKL's Optometrists Research Unit, Ramapuram, Chennai 600 089, India. kalikivayi@hotmail.com

2. Applied Optics Lab, Department of Physics, Indian Institute of Technology Madras, Chennai 600036, India.

\begin{abstract}
One of the important aspects of SPIE is "Community Support and Outreach Education", which should raise awareness and interest in optics and photonics among the targeted communities and school children. Hence as part of SPIE IIT Madras student chapter, we carried out SPIE SOAP, a 'School Outreach Activity Program'. Two types of schools were identified, one a high socio-economic status school and the other a low socio-economic status school having a majority of poor children. Optics related scientific experiments were demonstrated in these schools followed by oral quiz session to the students to assess the level of their knowledge before and after the experiments. We also clubbed this activity with "Vision Screening" and distribution of free spectacles for those children who live below poverty line. Out of the 415 children screened, $60.84 \%$ eyes were having normal vision, while $39.16 \%$ were found to have refractive errors (Myopia 35.78\% and Hyperopia 3.38\%) where some of them could not even read the board. Treatable eye diseases were also found in $0.72 \%$ of the children. The entire activity is been discussed and documented in this paper.
\end{abstract}

\section{INTRODUCTION}

One of the important aspects of SPIE is "Community Support and Outreach Education". This increases awareness in Optics \& Photonics among community and school children. As part of IIT Madras Student Chapter, we coined this activity as SOAP (School Outreach Activity Program). This activity is aimed at bringing the awareness of Optics and Photonics among the school children as well as providing "Vision Screening" as a service. It consists of the following 'Five Point Agenda'.

1. Every month, two schools will be identified, one a high socio-economic status school and the other a low socio-economic status school having a majority of poor children.

2. From each school, $9^{\text {th }}, 10^{\text {th }}, 11^{\text {th }}$ and $12^{\text {th }}$ standard students will be targeted. An Optics table will be set in the school and various experiments shall be demonstrated to motivate the students in Optics.

3. Simple contests will be conducted and the top three for each standard will be awarded Prizes.

4. As the best optics ever made is undoubtedly 'The Human Eye', a vision screening will be arranged for the students in the school, which will be done by hiring qualified Optometrists.

5. For socially economically backward schools, spectacles also will be provided to poor students at a cost as low as 10 US dollars.

\section{METHODS}

As part of SPIESOAP, our chapter members visitedschools to create awareness in Optics. Several experiments relatedto light and optics were carried to the schools for demonstration. All the students were made to assemble in

Optics Education and Outreach III, edited by G. Groot Gregory, Proc. of SPIE Vol. 9188,

91880I (C) 2014 SPIE · CCC code: 0277-786X/14/\$18 · doi: 10.1117/12.2061590 
one place for the demonstration of these experiments. Before demonstrating the experiments, a theoretical explanation of the experiments was given to the students by SPIE student chapter members. The theoretical explanation starts with the basics of light, types of light, wave theory of light, bending of light, diffraction of light, Laser basics and properties, Laser types, Holograms, application of Lasers in day today life and experiments to be demonstrate. After explaining the fundamental concepts, experiments were showcased to have a better understanding of the theoretical concept. Whilst explaining the basic concepts of light, each component and its functions are also explained simultaneously. The components shown and explained are plane mirror, lens, beam splitter, torch laser, polarizer and holographic grating plate.

One of the basic properties of light thatlight travels in a straight line was explained and demonstrated using a simple torch laser. The class room was completely covered and made it as a dark room. The torch laser was illuminated from one end of the class room to another end of the class room wall. The straight line path of the laser light was made visible to the students.

Another important property of light which is used in our day today application is bending of light. The bending of light was explained using a glass of water and a pencil. A plain glass tumbler was half filled with plain water and allowed it to settle down. Now the pencil was inserted into the half filled water glass. Due to the change in medium from air to water, the light takes different path, which gets reflected from the pencil and it made the pencil to look bent.

The basic components for any optical experiments like mirror, lens and beam splitters were explained. The laser pointer emits a narrow beam of light which was sent through a cube beam splitter. The beam splitter splits the laser light into two, one as reflected beam and another as transmitted beam. This experiment was also conducted in a dark room.

A simple interference using a grating sheets were also shown and explained its application. Using a grating, the concept of diffraction was shown and explained. Fourier synthesis of an image was demonstrated showing commercially available Fourier gratings of some images.

Apart from these, dispersion of white light was explained using a prism. It was simple to demonstrate. By illuminating a white torch light into the triangular prism, the dispersion pattern was observed on the other end and it was shown and explained.

All the children who attended the activity were of the age between 12-15 years. After the experiment session, students were asked to participate in quiz program. Questions were asked regarding the experiments conducted at the school. All the children participated with great enthusiasm and won prizes and gifts (Fig 1). The students who answered more number of questions were given gifts or prizes like pens, pencils, note books, markers, geometry boxes etc.

As the best optics ever made is human eye, along with the experiments and the quiz session, eye examinations were also performed to all the children. The eye examination included visual acuity measurement using Snellen's Chart, streak retinoscopy, subjective refraction, slit lamp examination and direct ophthalmoscopy. All the children's data was stored and analyzed for the prevalence of refractive errors. All the eye examinations were conducted at the schools by qualified optometrists. This study followed the tenets of the Declaration of Helsinki and was approved by Institutional review board and ethics committee. 


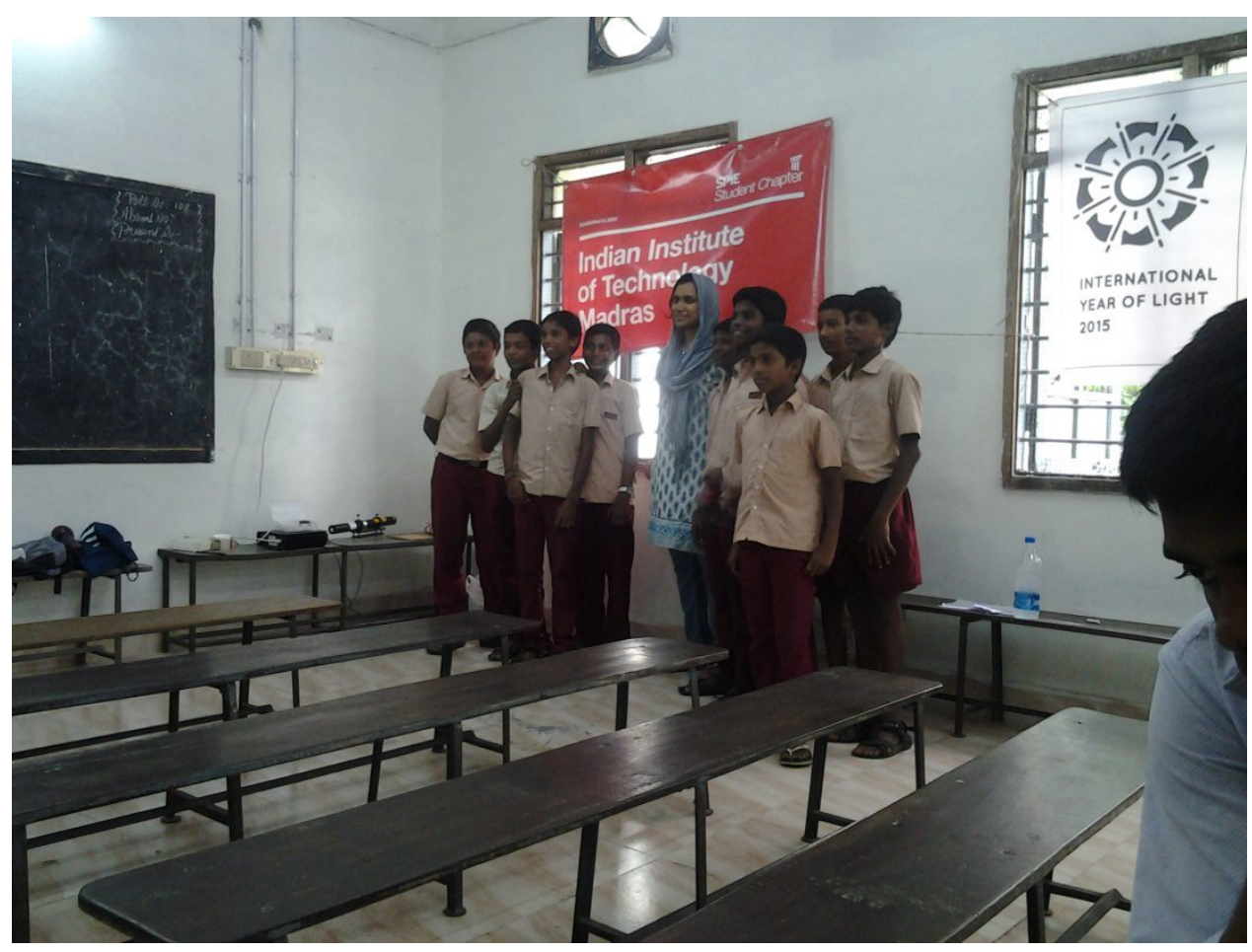

Fig 1: Few students who won prizes in the quiz program.

A child with unaided visual acuity of 20/20 is considered as Emmetropia. Spherical Equivalent (SE) is calculated as the sum of the sphere and half the cylinder. Myopia is defined as SE $-0.75 \mathrm{D}$ or less. Hyperopia is defined as +0.75 $\mathrm{D}$ or more. Mild, moderate and severe myopia or hyperopia is defined as SE +/- 0.75 to $+/-3.00,+/-3.25$ to $+/-6.00$ and $+/-6.25$ or more respectively. Astigmatism is defined as $+/-0.75$ or more. As the refractive errors less than $+/-$ 0.75 are also making significant contribution in increasing the vision as well as reducing the asthenopic symptoms, we coined a new group of refractive errors called as Precinct Refractive errors. A Precinct Myopia is defined as SE 0.12 to -0.62 . A Precinct Hyperopia is defined as $\mathrm{SE}+0.12$ to +0.62 . Precinct Astigmatism is defined as $+/-0.25$ to $+/$ - 0.62.Table 1 shows the classification of above definitions.

\begin{tabular}{|l|l|}
\hline \multicolumn{1}{|c|}{ Refractive Error } & \multicolumn{1}{c|}{ Spherical Equivalent } \\
\hline Myopia & $-0.75 \mathrm{D}$ or less. \\
\hline Hyperopia & $+0.75 \mathrm{D}$ or more \\
\hline Astigmatism & $+/-0.75$ or more \\
\hline Mild Myopia or Hyperopia & $+/-0.75$ to $+/-3.00$ \\
\hline Moderate Myopia or Hyperopia & $+/-3.25$ to $+/-6.00$ \\
\hline Severe Myopia or Hyperopia & $+/-6.25$ or more \\
\hline Precinct Myopia & -0.12 to -0.62. \\
\hline Precinct Hyperopia & +0.12 to +0.62 \\
\hline Precinct Astigmatism & $+/-0.25$ to $+/-0.62$ \\
\hline
\end{tabular}

Table 1: Classification of refractive errors. 


\section{STATISTICAL ANALYSIS}

A statistical analysis was performed by using Microsoft Excel data analysis. Independent $t$ test and correlation tests were mainly used to analyze $\mathrm{P}$ values and correlation coefficients. To find out the statistical significanceP values are commonly used in statistical hypothesis tests. In this work, we have taken the significance level at $95 \%$ or 0.05 as a reference point. A P valueless than 0.05 indicates that the results are very significant and the event did not happen by chance.

\section{RESULTS}

Eye examination was carried out for a total of 415 children with age range of 10 to 18 years with the mean of 14.63 years. There were 204 boys and 211 girls. Fig 2 shows an Optometrist performing subjective refraction.

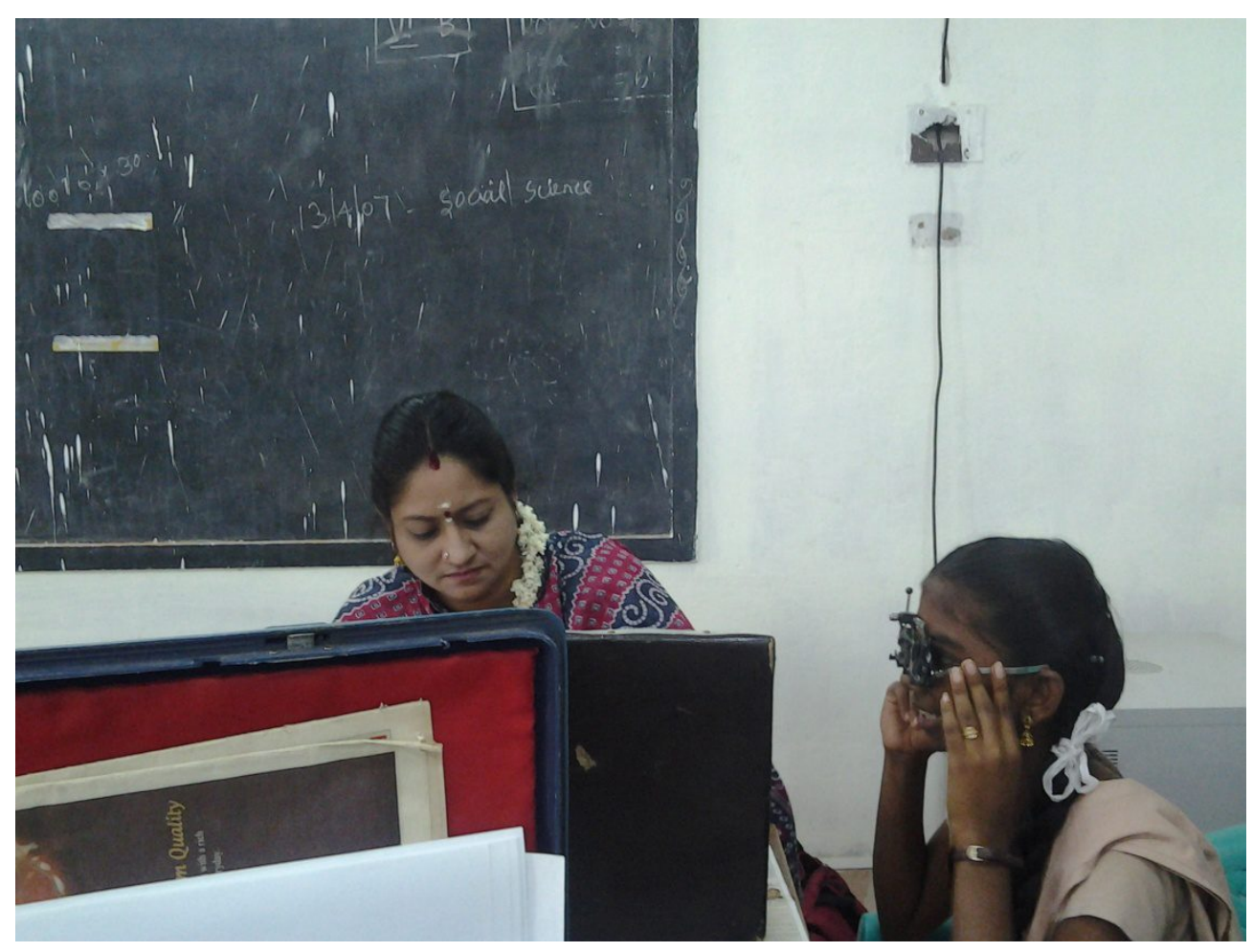

Fig 2: Optometrist performing subjective refraction.

Of 830 eyes, Emmetropia, Myopia and Hyperopia were found in 505 (60.84\%), 297 (35.78\%) and 28 (3.38\%) eyes respectively. Figure 3 shows the histogram of different refractive errors diagnosed in this activity. 


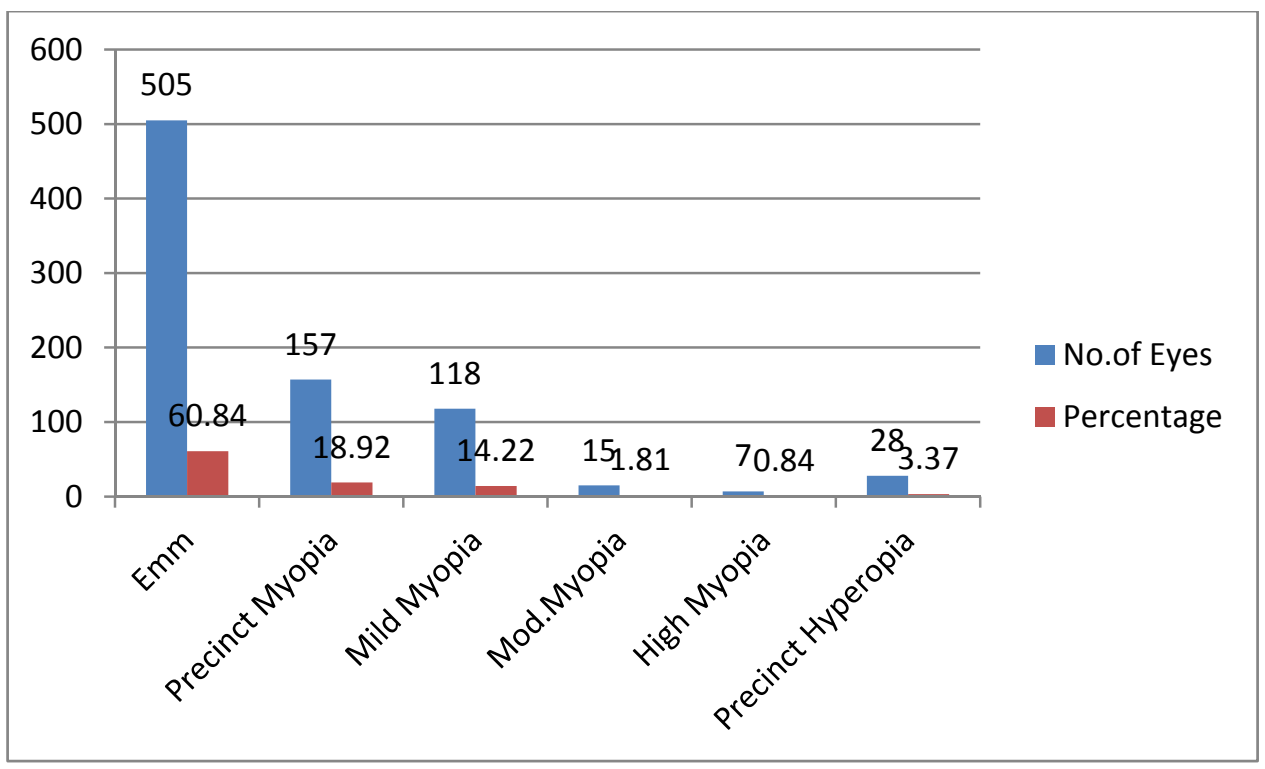

Fig 3: A bar graph of different refractive errors.

The mean values for Precinct myopia, mild, moderate, high myopia and precinct hyperopia were found to be - $0.32,-$ $1.47,-4.38,-7.36$ and 0.25 respectively. The mean, standard deviation and range of all refractive errors are given in Table 2.Astigmatism was found in $58(6.99 \%)$ eyes, where as precinct astigmatism was found in $99(11.93 \%)$ eyes. Hyperopia was not found in any of the children.

\begin{tabular}{|c|c|c|c|c|c|c|}
\hline & Emm & Precinct Myopia & Mild Myopia & $\begin{array}{c}\text { Moderate } \\
\text { Myopia }\end{array}$ & High Myopia & Precinct Hyperopia \\
\hline No.of Eyes & 505 & 157 & 118 & 15 & 7 & 28 \\
\hline Percentage & 60.84 & 18.92 & 14.22 & 1.81 & 0.84 & 3.37 \\
\hline Mean & - & -0.32 & -1.47 & -4.38 & -7.36 & 0.25 \\
\hline SD & - & 0.12 & 0.74 & 0.73 & 0.89 & 0.06 \\
\hline Minimum & - & -0.62 & -3 & -6 & -9 & 0.12 \\
\hline Maximum & - & -0.12 & -0.75 & -3.25 & -6.5 & 0.5 \\
\hline
\end{tabular}

Table 2: Distribution of refractive errors among 830 eyes.

Of 415 children, $22(5.3 \%)$ were already wearing the spectacles and $181(43.6 \%)$ were given new spectacles at 10 US dollars per spectacle with unbreakable lenses. Figure 4 shows a student selecting a spectacle frame. 


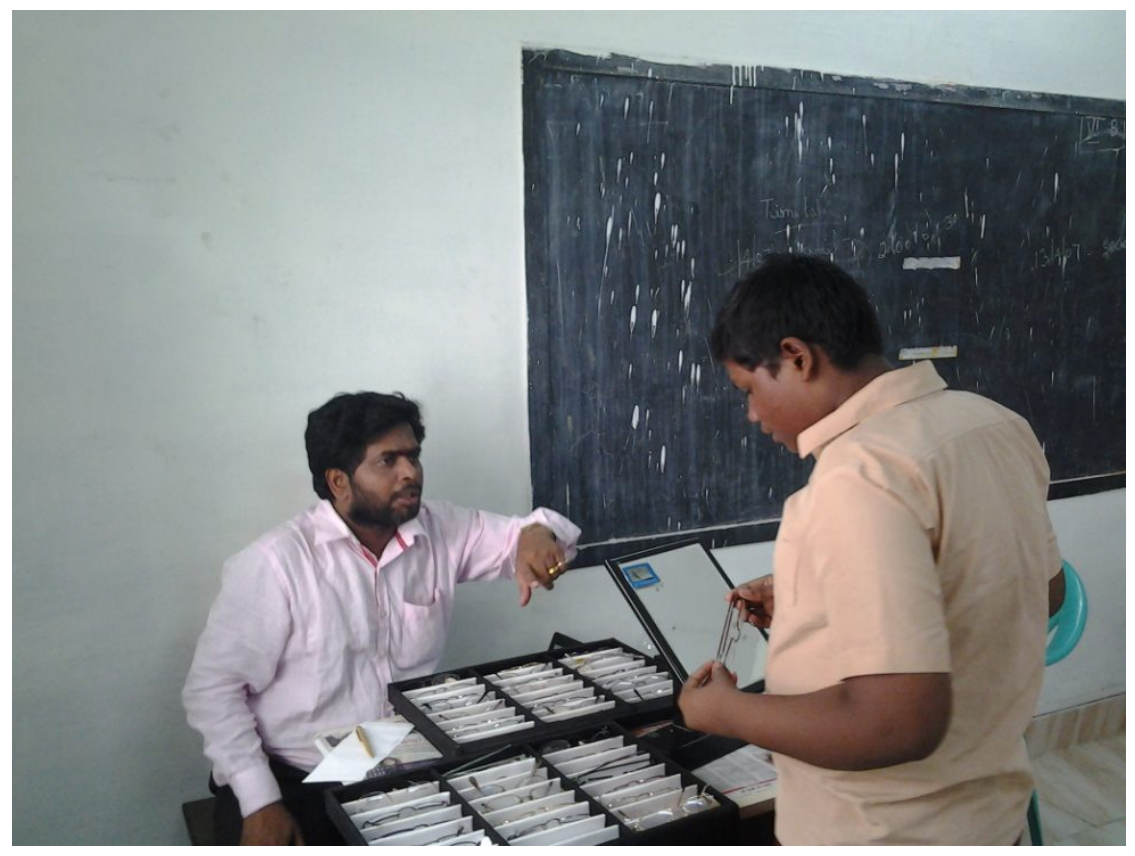

Fig 4: Frame selection by a student

There is a statistically significant $(\mathrm{p}<0.05)$ positive correlation between age and Myopia, which is shown in Figure 5 with the "Regression Line".

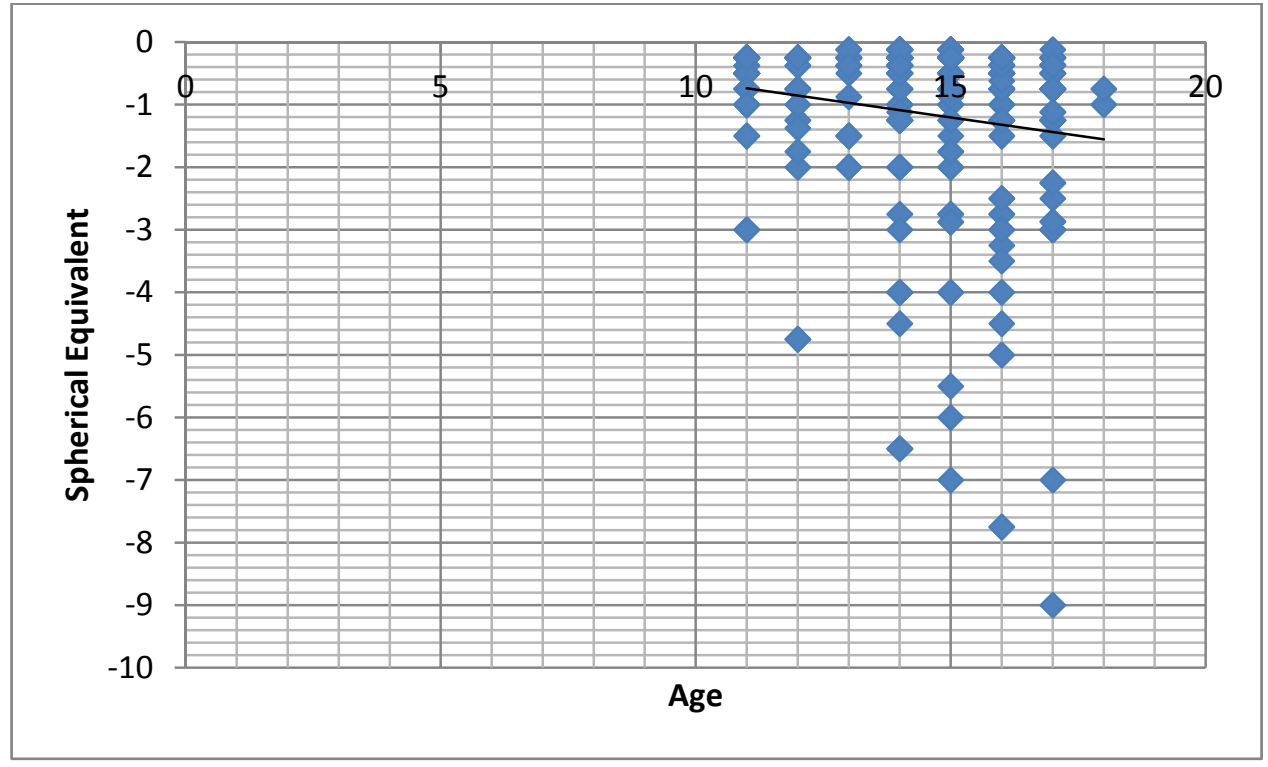

Fig 5: Correlation between age and spherical equivalent. 


\section{DISCUSSION}

As per UN 2013 report [1], one third of the world's poor live in India. The estimated results of World bank shows that $68 \%$ of the population live on less than US\$ 2 a day. The Oxford Poverty and Human Development Initiative (OPHI) in 2010 states that 8 Indian states have 421 million poor people [2,3]. The United Nations Development Program in 2010 states $29.8 \%$ of Indians live below the country's national poverty line [4].

The World Health Organization reports visually impaired in developing countries are estimated to be approximately 517 million people. The primary reason was that they do not have access to corrective treatment. The simple treatment for this is a simple, old and cost effective technology is "A pair of Spectacles or Eye glasses".

Visual impairment has economic, educational, and public safety implications. In India during $2000,7 \%$ of the population wore spectacles and $65 \%$ of the population needed them [5]. The main challenges for this visual impairment are a lack of awareness, affordability and access to eyeglasses. The principal barriers to eye care in Andhra Pradesh, India in 2006 study reported that $23.8 \%$ of the 2,615 respondents believed they did not have a serious vision problem, $23.4 \%$ stated that they were able to see adequately, $20.4 \%$ had other obligations which prevented an eye checkup, and $17.5 \%$ did not have enough money [6].

In this SPIE SOAP activity, the estimated children who needed vision correction is found to be $43.6 \%$, whereas only $5.3 \%$ were already wearing spectacles. This shows the need and importance of continuing this activity. In this SPIE sponsored activity 181 children got benefited.

\section{CONCLUSION}

This signifies the importance of this SOAP activity which received a tremendous and encouraging response from the schools including the teachers and children. It not only created awareness in Optics among school children but also provided "Good Vision". Hence it is important to continue this activity not only in India but also in the other parts of the world. We have a group of Optometrists working in our research unit. Any SPIE student chapter can contact our first author to discuss in detail about this activity as we are willing to extend our support in continuing this activity.

\section{ACKNOWLEDGEMENT}

We sincerely acknowledge SPIE for providing "Outreach Activity Grant" for supporting the SOAP activity.

\section{REFERENCES}

[1] World Bank, "India has one third of world's poorest". TheTelegraph.

[2] The Times of India , " 8 Indian states have more poor than 26 poorest African Nations", (12 ${ }^{\text {th }}$ July, 2010).

[3] BBC News, "More poor in India than Africa", (13 July, 2010).

[4] Jay Mandal. "Poverty Reduction", "http://www.undp.org.in/whatwedo/poverty_reduction.

[5] Bernard Garrette, KarimBenkirane, and C. Roger-Machart, "Essilor's "Base of the Pyramid' Strategy in India" HEC Paris, (2008).

[6] Praveen K. Nirmalan, SannapaneniKrishnaiah, Bindiganavale R. Shamanna, et al., "A Population-Based Assessment of Presbyopia in the State of Andhra Pradesh: The Andhra Pradesh Eye Disease Study," Investigative Ophthalmology \& Visual Science, (2006). 